\title{
Quality Assurance Support (QA/QC System) of Mineralogical Analysis
}

\author{
O. Yakushina ${ }^{(凶)}$, E. Gorbatova, E. Ozhogina, and A. Rogozhin \\ FSBE “All-Russian Institute on Mineral Raw Materials” (VIMS), \\ Moscow, Russia \\ vims@df.ru
}

\begin{abstract}
Mineralogical studies are an integral part of the exploration and development of solid mineral deposits, the effectiveness of which directly depends on the quality of the measurements. Moreover, five decades QA/QC system of mineralogical analysis (UKARM) for Russian geological survey is developed. Its specific features and tasks are discussed. The system provides to obtain complete, reliable, metrologically evaluated and legally valid information about the material composition and structure of rocks and ores. QA/QC of mineralogical analysis ensures the coordination of testing laboratories, starting with the resources of testing laboratories, stuffing at last. This system covers the entire process of mineralogical research, starting at the resources of testing laboratories as stuff and equipment, through the research procedure as the selection of testing object and its preparation for analysis, the accuracy of analysis rank, the testing method and technique, to metrology data and the quality assessment of the results obtained.
\end{abstract}

Keywords: Mineralogical analysis - Quality management • Assurance · Control system $\cdot$ Metrology $\cdot$ Reference materials

\section{Introduction}

Mineralogical analysis is an integral part of mineral deposits exploration and development; its effectiveness directly depends on the quality of testing (ISO/IEC 17025:2005; JORC Code 2012). The quality of analysis directly affects efficiency and reliability of the whole investigation. The main requirement for mineralogical research is to obtain reliable, complete, metrologically evaluated and legally valid information about the studied matter composition and structure, namely of rocks, ores and technologically processed products. The quality management system of mineralogical works ensures the coordination of testing laboratories, starting with the resources of testing laboratories, and ending with the processes occurring in them. Laboratory mineralogical studies with varying degrees of depth of mineral substance analysis are carried out at all stages of geological exploration from geological prospecting to operational exploration and development of mineral deposits. The main requirement for laboratory mineralogical studies is to provide all spheres of activity of the Ministry of Natural Resources and Ecology of the Russian Federation with reliable, 
reliable, standardized, metrologically evaluated and legally valid information obtained as a result of the use of a wide range of laboratory methods and equipment (Ozhogina et al. 2017a, b).

\section{Methods}

The variety and complexity of objects of natural and man-made origin, the widespread use of quantitative methods of mineralogical analysis, the presence of a large number of mineralogical laboratories with different instrumentation and methodological base, personnel composition, determines the need to improve and develop the Quality Management System QA/QC for Mineralogical works UKARM, established at VIMS in the 1980th (Ginsburg et al. 1985) and renovated today. Developed by VIMS the UKARM System coordinates laboratory studies, preparation for testing operations and also monitors the quality of research. Scientific-methodical support of the UKARM functioning carries out the Scientific Council on methods of mineralogical methods of analysis (NSOMMI). The main components of UKARM mineralogical QA/QC system include as follows:

- make the General concept of development of mineralogical service and deliver priority directions of its improvement;

- preparation of proposals for the program and coordination plan of scientific research aimed at solving mineralogical laboratory research methods of testing;

- develop the industry system of standard samples, coordinate their production, registration and use;

- the NSOMMI Scientific Council review, update and elaborate new guidance documents on methods of all kinds of laboratory mineralogical works, the system and means of these documents verification and approval;

- ensuring the functioning of a unified quality management system of laboratory mineralogical work, organization and carrying the interlaboratory comparative tests (ICT), internal and external laboratory analysis control;

- methodological assistance support for the basic and regional laboratories and research centers in certification of mineralogical methods of analysis;

- implementation of complex and unique mineralogical and analytical studies;

- development of operational information system for mineralogical research.

UKARM QA/QC system is based on the requirements of the requirements of ISO/IEC 17025 standard in relation to mineralogical research, starting with the resources as stuff and equipment, ending with metrology and data quality assessment (Fig. 1). The testing laboratory stuff must have the necessary competence to perform at a high level of mineralogical works. UKARM QA/QC includes workshops, advanced training courses for laboratory stuff. For example, every year, since 2011, VIMS arrange annual Seminar "Mineralogical school - Current problems and modern methods". Seminar members discuss the basic state-of-art concepts of mineralogy, prospects of development, mineralogical support of geological exploration, methods of mineralogical analysis, environmental problems, specific features of man-made raw materials study, mineralogy for enrichment of ores, the nature of minerals technological 
properties and their behavior in geological and technological circulation, mineralogical works metrological and methodological support, etc. Specialists of various affiliation took part in the Seminar.

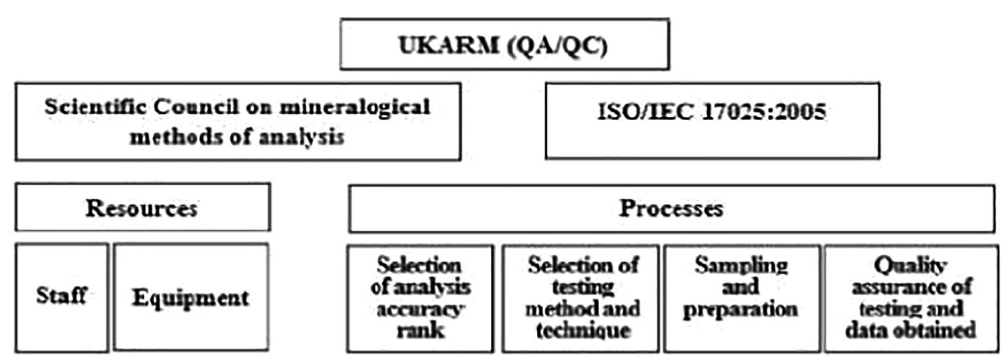

Fig. 1. UKARM QA/QC system structure

Testing laboratories are equipped with the necessary units: measuring instruments, software, standards, reference data, reagents and consumables. Also the methodical base is developed or adapted to technical base of analysis current state, corresponding metrological assessment and its legal approve. The certification and registration of standard samples of phase composition and properties, and artificial mixtures is also a necessary element of QA/QC. The choice of mineral substance testing method and mode is determined by substance peculiarities in composition and structure, the hardware capabilities, the availability of relevant methodological documents and the staff competence. In 2018 the Register on mineralogical studies of natural or technogeneous mineral raw matter includes 3 industry standards, 45 instructions, 31 practical guidelines and 174 recommendations.

Today, the methods of quantitative phase analysis of rocks, ores and man-made substance are especially in demand. UKARM QA/QC includes the classification of quantitative phase analysis laboratory methods, depending on their reproducibility, are divided into six categories: I - particularly accurate quantitative analysis, II - full phase analysis with increased accuracy, III - ordinary quantitative analysis, IV - ordinary analysis with reduced accuracy requirements (express), V - semi-quantitative analysis, VI - qualitative phase analysis. Any testing may/should be characterized by a level of accuracy (Ozhogina et al. 2017a, b).

\section{Results and Discussion}

The quality of measurements is provided by measuring units' verification and calibration tests; the availability of measurement guidance and their strict observance; internal and external laboratory control. Organization of the control and dispatching service for mineralogical analysis and interlaboratory comparative tests, carrying out the control of phase composition and properties by standard samples, certified 
mixtures; participation in analysis to certify the standard samples of phase composition and properties, certification of laboratories with mandatory experimental evaluation.

We state the leading role and the one of the most effective forms of external control are Interlaboratory Comparative testing (ICT). The last one allow to evaluate the reliability of the results obtained in each individual laboratory, and to obtain information about the real accuracy of measurement techniques in general. In 2016-2018 VIMS conducted a series of ICT on X-ray powder diffraction (XPD) and petrography analysis. The samples for control were artificial mixture of minerals (2), and synthetic corundum powder (1), igneous (1) and sedimentary (1) rocks thing-sections. Each ICT involved from 8 to 12 participants, totally 46 laboratories. The obtained results are considered satisfactory, they can be used by laboratories during accreditation procedures and confirmation of technical competence. The ICT comparative testing provide an opportunity to assess the quality of measurements in different laboratories, to carry out corrective actions to ensure the uniformity of measurements and to show the technical competence of the laboratory.

\section{Conclusions}

Mineralogical study of any substance should be based on a QA/QC System. Testing laboratory, which performs mineralogical studies supporting geological exploration and technological works in order to meet the requirements of mineralogical work quality management should have the relevant stuff, modern test methods, proper equipment, capabilities and means of verification and calibration, be supplied by industry techniques procedures, guidelines, as well as strictly follow them, and comply with the requirements of a unified quality control system.

\section{References}

Ginsburg AI, Vikulova LP, Sidorenko GA (1985) On some typical mistakes at mineralogical investigation (studies) J. In: Zapiski RMO (Proceedings of RMS), vol 3, pp 324-333

JORC Code: 2012 Edition. http://jorc.org/

ISO/IEC 17025:2005: General requirements for the competence of testing and calibration laboratories

Ozhogina EG, Gorbatova EA (2017a) System of mineralogical quality management. J Actual Probl Min 1:3-7

Ozhogina EG, Lebedeva MI, Gorbatova EA (2017b) Interlaboratory comparison tests in the mineralogical works. J. Stand. Samples 2:37-47 
Open Access This chapter is licensed under the terms of the Creative Commons Attribution 4.0 International License (http://creativecommons.org/licenses/by/4.0/), which permits use, sharing, adaptation, distribution and reproduction in any medium or format, as long as you give appropriate credit to the original author(s) and the source, provide a link to the Creative Commons license and indicate if changes were made.

The images or other third party material in this chapter are included in the chapter's Creative Commons license, unless indicated otherwise in a credit line to the material. If material is not included in the chapter's Creative Commons license and your intended use is not permitted by statutory regulation or exceeds the permitted use, you will need to obtain permission directly from the copyright holder.

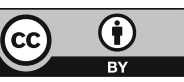

